\title{
The Seismic Source Parameters of Tremors Provoked by Long-Hole Destress Blasting Executed During the Longwall Mining of a Coal Seam Under Variable Stress Conditions
}

\author{
Łukasz Wojtecki, ${ }^{1}$ (D) Maciej J. Mendecki, ${ }^{2}$ (D) Iwona Gołda, ${ }^{3}$ (D) and Wacław M. Zuberek ${ }^{2}$ (D)
}

\begin{abstract}
The underground mining of coal seams in the Upper Silesian Coal Basin is carried out at great depths and mostly in the presence of remnants or edges of other surrounding coal seams, i.e. under the condition of high stress level in the rock mass. Therefore, this mining is accompanied by rockburst hazard and suitable preventive action is required. Long-hole destress blasting plays an important role and is commonly applied in rockburst prevention in underground hard coal mines. Estimated blasting effectiveness is important when designing rockburst prevention. It is commonly estimated on the basis of the seismic energy of a provoked tremor. The seismic source parameters have already been considered for this purpose. Additional information about the effects of long-hole destress blasting could be contemplated in the planning of active rockburst prevention. The seismic source parameters of tremors provoked by long-hole destress blasting have been calculated and are presented in this article. Destress blasts were performed during the longwall mining of coal seam no. 506 in one of the hard coal mines in the Upper Silesian Coal Basin. They were executed from the longwall face, in order to destress the rock mass ahead of it. Parameters of the blasts were variable and they were modified according to geological and mining conditions and the observed level of rockburst hazard. The seismic source parameters have been determined for tremors provoked directly after firing explosives and for tremors occurring in the waiting time, and they have been compared with each other.
\end{abstract}

Keywords: Seismic source parameters, long-hole destress blasting, rockburst prevention.

\section{Introduction}

Rockburst hazard accompanies underground coal mining in the Upper Silesian Coal Basin (USCB). There are many reasons for rockburst occurrence, but among the most important are the depth of mining and the presence of remnants or edges of previously mined coal seams. These factors are responsible for high stress levels in the rock mass and have an effect on the occurrence of the rockburst phenomenon. To minimize rockburst hazard, active rockburst prevention must be applied. To release the stress accumulated in the rock mass, long-hole destress blasting is executed. The explosive material is loaded into a single blasthole or more often into several blastholes, drilled from an opening, usually in the roof rocks of coal seams. The length of these blastholes usually equals a significant number of meters, and sometimes even over one hundred meters. The blasting charge in a single blasthole equals usually tens of kilograms, but sometimes it can exceed one hundred kilograms. During a single blast a total mass of hundreds of kilograms, loaded into several blastholes, can be fired. The main aim of the long-hole destress blasting is to fracture thick layers of competent roof rocks, leading to a reduction of stress concentrations in the rock mass, at a close distance from underground excavations. As a result of blasting, the strain energy accumulated in the rock mass can be released. Moreover, the fracturing of rock mass prevents or minimizes the negative dynamic influence of high-energy tremors on excavations. The long-hole destress blasting executed in hard coal mines usually provokes tremors immediately, but sometimes they can come after some delay, in the waiting time.
1 Central Mining Institute, 1 Gwarków Square, 40-166 Katowice, Poland. E-mail: 1wojtecki@gig.eu

2 Faculty of Environmental Sciences, University of Silesia in Katowice, 60 Będzińska Str. 41-200, Sosnowiec, Poland. E-mail: maciej.mendecki@us.edu.pl; waclaw.zuberek@us.edu.pl

3 Faculty of Mining, Safety Engineering and Industrial Automation, Silesian University of Technology, 2 Akademicka Str. 44-100, Gliwice, Poland. E-mail: iwona.golda@polsl.pl 
The seismic energy of provoked tremors is currently the main parameter for the estimation of destress blasting effectiveness in hard coal mines (Knotek et al. 1985; Konicek et al. 2011, 2013; Wojtecki and Konicek 2016). If this energy is high that it would be expected from the mass of the explosives fired, it indicates the occurrence of additional processes.

Seismic source parameters give more complete information about processes occurring in the foci of tremors and their scale. These parameters, commonly calculated for natural seismic events or tremors induced by mining, can be determined for tremors provoked by long-hole destress blasting (Srinivasan et al. 2005; Wojtecki et al. 2017a, b) or blasting for roof falling (Wojtecki et al. 2019). These parameters provide additional information about blasting effects. They can be used in determining blasting effectiveness, as well as in the standard calculation of seismic energy. Moreover, we applied PPV for this purpose as well. In this article, analysis of the seismic source parameters of tremors provoked by long-hole destress blasting, during the longwall mining of coal seam no. 506 in one of the hard coal mines in the Polish part of the Upper Silesian Coal Basin and associated PPV, has been performed.

\section{Geological and Mining Conditions}

A longwall with caving was planned in coal seam no. 506, under the extracting level. In the longwall panel, coal seam no. 506 was deposited at a depth from approximately 1000-1050 m below the surface, which led to a high stress level (theoretically of about $26 \mathrm{MPa}$ ). The longwall mining of coal seam no. 506 started from a longwall cross-cut, located on the east side of the mining area. The longwall cross-cut was drilled near the downthrow side of a fault with a throw of $50 \mathrm{~m}$. The longwall face was advanced in the western direction. Longwall mining of coal seam no. 506 ended near the border of the protecting pillar for drifts, in the middle of the mining area. The longwall panel was placed to the north of a goaf made by an earlier extraction of coal seam no. 506. The goaf and longwall panel were separated by a rib of coal, about $5 \mathrm{~m}$ wide. A deflection of rock layers above the border of the goaf was responsible for the clamping of the tail gate of the selected longwall, therefore it was necessary to drill an additional tail gate at some distance.

The thickness of the coal seam no. 506 in the longwall panel varied. Near the longwall cross-cut it equalled about $2.5 \mathrm{~m}$ (because of the joint with coal seam no. 505/1). At the end of the longwall panel, the thickness of the coal seam no. 506 equalled $1.4-1.65 \mathrm{~m}$, and it was separated from coal seam no. $505 / 1$ of a thickness $0.65-0.95 \mathrm{~m}$, by a layer of shale with a thickness of $0.8 \mathrm{~m}$. The dip angle of the coal seam no. 506 equalled $5-12^{\circ}$ and was generally to the south.

In the longwall panel, the floor of coal seam no. 506 was composed of a thin layer of shale and sandy shale. A layer of sandstone was deposited below. In the direct roof of coal seam no. 506, shales and sandy shales mostly occurred, but in places, sandstones were present too. At larger distances from coal seam no. 506, three thick layers of sandstones occurred: approximately $39 \mathrm{~m}$ above (layer with a thickness of about $11 \mathrm{~m}$ ), approximately $60 \mathrm{~m}$ above (layer with a thickness of about $26 \mathrm{~m}$, interbedded with 3 thin layers of sandy shale: $0.3,0.4$ and $0.8 \mathrm{~m}$ ), and approximately $104 \mathrm{~m}$ above (layer with a thickness of about $22 \mathrm{~m}$ ). The uniaxial compressive strength of these sandstones reaches maximally almost $80 \mathrm{MPa}$. In the roof rocks, additional stress occurred due to the negative influence of the remnant of coal seam no. 418 (130-141 $\mathrm{m}$ above coal seam no. 506) and the edge of coal seam no. 502 (60-82 m above seam no. 506). In some parts of the longwall panel, the remnant and edge were both presented.

\section{Seismic Observations and Rockburst Hazard During Longwall Mining of Coal Seam No. 506}

The area of longwall panel was monitored by the mine seismological network, consisting of 16 seismic stations placed in underground excavations at depths from 320 to $1000 \mathrm{~m}$ below the surface. The network was composed mainly of vertical SPI-70 seismometers and also of DLM-2001 geophones, installed on bolts and oriented vertically. The sensors used measure the velocity of rock mass motion. These sensors 
measured seismic signals with a minimal frequency of about $1 \mathrm{~Hz}$. The observation system could monitor seismic events with energy greater or equal to $10^{2} \mathrm{~J}$. The registration and processing dynamics of the system was equal to or less than $72 \mathrm{~dB}$. Each channel had its own amplitude gain. The timing of the mine seismological system was synchronized by the Global Positioning System.

The average error of epicenter location ranges from about 30 to about $50 \mathrm{~m}$, while the average error of the hypocenter location ranges from about 60 to about $70 \mathrm{~m}$. Generally, the error of seismic source location increases to the east, because of the configuration of the seismic stations, which were placed mostly to the west and north-west (Fig. 1).

The seismic energy of tremors $E$ was calculated using the numerical integration method. In this method, it is assumed that the seismic energy is proportional to the area under the seismogram. In order to determine the correct value of the seismic energy, it is necessary to use the records of rock mass motion at frequency range characteristic for mine tremors. Generally, it is not possible to design a sensor covering the total frequency range, therefore instruments with different frequency responses are used for different frequency ranges. Moreover, the type of sensor to be used is also determined by the ranges of amplitude to be measured and the distance between sensor and focus of mine tremor. On the amplitude-frequency characteristics of seismic sensors used in this study the plateau begins around a few hertz and extends to higher frequencies, up to at least $100 \mathrm{~Hz}$. The frequency analysis of the recorded signals based on the FFT method showed that in the highest frequencies they reach the value of several dozen hertz, but lower than $100 \mathrm{~Hz}$. It can be assumed that the entire frequency band of seismic waves, emitted from the area of blasting works, has been correctly recorded, and the signal didn't have amplitude distortion. When using the numerical integration method, the square of the amplitude in the following samples between the start and end markers, the sampling rate $(200 \mathrm{~Hz})$, the density of the rock mass $\left(2600 \mathrm{~kg} / \mathrm{m}^{3}\right)$, the attenuation of the rock
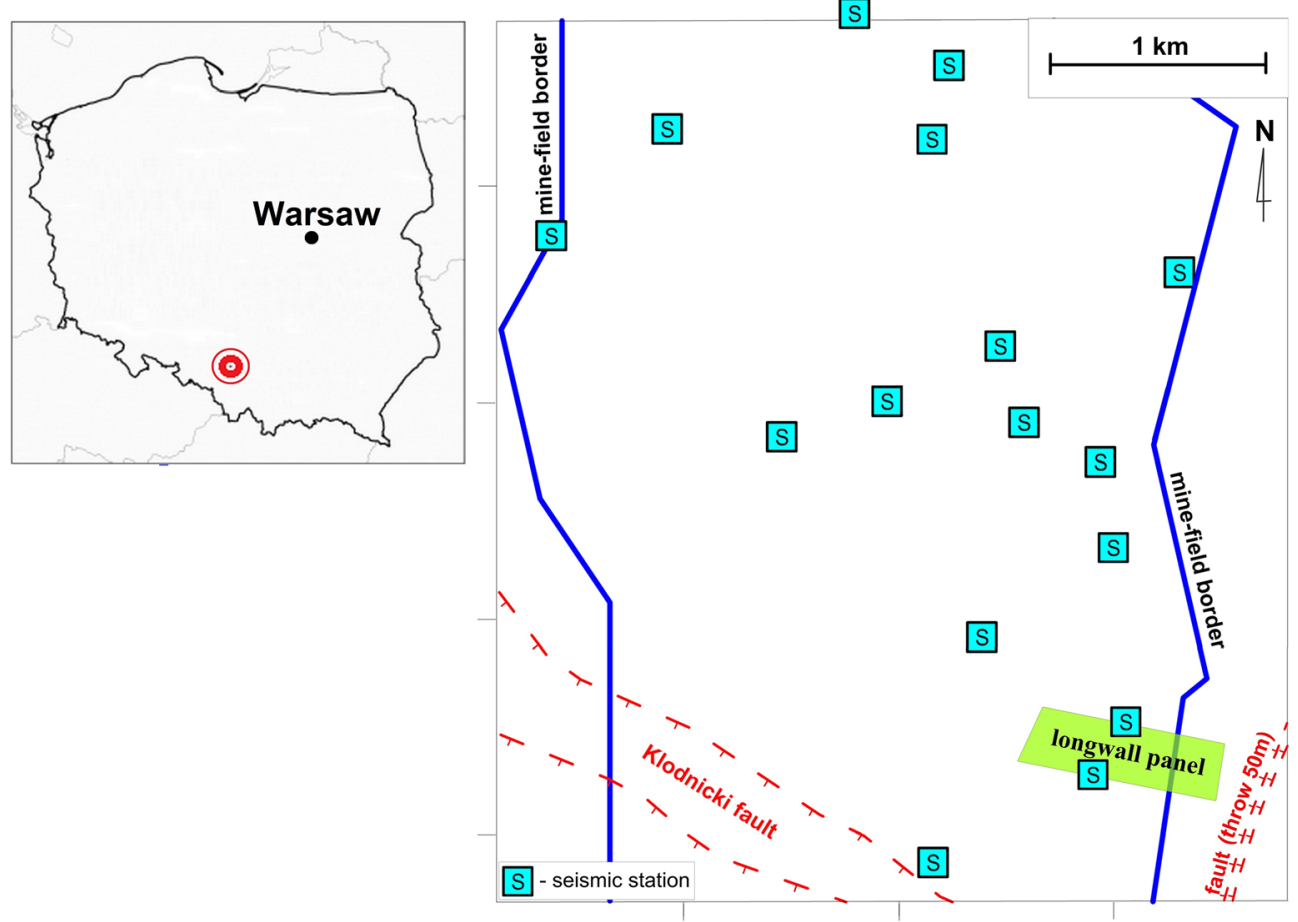

Figure 1

Distribution of seismic stations in relation to the longwall panel location 
mass - quality factor (with a typical value of 30), the calibration factor calculated for each station, the distance between the focus and the seismic station, and directional seismic wave velocity (mostly of about $3800-4100 \mathrm{~m} / \mathrm{s}$ ) were taken into account for the calculation of the seismic energy at each of the seismic stations (Wojtecki and Gołda 2019). The energies of all the seismic stations were arithmetically averaged providing the final seismic energy of each tremor. The seismic energy of the provoked tremors was calculated in an analogous manner. The values of the local magnitude $M_{L}$ were calculated with the use of seismic energy according to the formula given by Dubiński and Wierzchowska (1973):

$$
\log E=1.8+1.9 M_{L}
$$

The total number of registered seismic events, induced by the longwall mining of coal seam no. 506 was 5873, with a total released tremor energy of $1.516 \times 10^{8} \mathrm{~J}$, including 4360 tremors with energy of $10^{2} \mathrm{~J} \quad\left(0.11 \leq M_{L}<0.63\right), 1054$ tremors with energy of $10^{3} \mathrm{~J}\left(0.63 \leq M_{L}<1.16\right) ; 381$ tremors with energy of $10^{4} \mathrm{~J}\left(1.16 \leq M_{L}<1.68\right), 57$ tremors with energy of $10^{5} \mathrm{~J}\left(1.68 \leq M_{L}<2.21\right), 19$ tremors with energy of $10^{6} \mathrm{~J}\left(2.21 \leq M_{L}<2.74\right)$ and two tremors with energy of $10^{7} \mathrm{~J}$, i.e. $1 \times 10^{7} \mathrm{~J}\left(M_{L}=\right.$ 2.74) and $2 \times 10^{7} \mathrm{~J}\left(M_{L}=2.9\right)$.

The fracturing of the aforementioned thick layers of competent rocks, especially within the area under the influence of the remnant of coal seam no. 418 and the edge of the coal seam no. 502, was responsible for high energy tremors occurrence. The presence of high-energy tremors, i.e. with the energy of $10^{5} \mathrm{~J}$ and higher, greatly increased the level of rockburst hazard in the selected longwall. Under the conditions mentioned above and according to technological opportunities it was necessary to plan and execute active rockburst prevention.

\section{Active Rockburst Prevention in the Selected Longwall}

Rockburst hazard in the selected longwall panel was minimized by the active rockburst prevention, based on long-hole destress blasting in roof rocks. Blasts were executed mainly from the longwall face.
The diameter of the blastholes equalled $76 \mathrm{~mm}$. Because of methane hazard, a special methane explosive material-Emulinit PM was used. The heat explosion of this explosive material equalled $2278 \mathrm{~kJ} / \mathrm{kg}$, and the specific volume of gaseous products of the explosion equalled $767 \mathrm{dm}^{3} / \mathrm{kg}$ (https://www.nitroerg.pl). The minimum velocity of the detonation was $4000 \mathrm{~m} / \mathrm{s}$ (https://www.nitroerg. $\mathrm{pl})$. Immediate methane electric detonators were used to initiate the explosion. During each blast, explosives loaded into blastholes were fired at the same time, without any delay.

The destress blasts were executed to achieve the maximal destress effect in the rock mass ahead of the longwall face and near the longwall galleries. Rockburst prevention in the longwall panel was focused on blasting in roof rocks, executed from the longwall face, and intensified below the remnant of coal seam no. 418 and the edge of the coal seam no. 502. Due to technological opportunities, the first thick layer of sandstones $(11 \mathrm{~m})$ was attainable.

In total 47 blasts were executed from the longwall face (Fig. 2). In all cases, tremors were provoked immediately, and in 4 cases aftershocks occurred. The parameters of blasts were modified in accordance with the geological and mining conditions and the observed level of rockburst hazard.

The first blast was executed before the longwall mining had started. In the four blastholes, arranged in two pairs, a total of $288 \mathrm{~kg}$ of explosives $(72 \mathrm{~kg}$ per blasthole) was loaded. The blastholes deviated from the longwall cross-cut to the north-east and south-east at an angle of about $30^{\circ}$, and they were drilled outwards from the longwall panel. The blastholes were $45 \mathrm{~m}$ long and were inclined upwards at an angle of 45 to the horizon. Explosive material occupied about $15 \mathrm{~m}$ of each blasthole, and the rest was filled with stemming. The column of the explosives was located in the roof rocks of coal seam no. 504, composed of alternating layers of sandstones, sandy shales and shales. The seismic energy of the provoked tremor equalled $3 \times 10^{4} \mathrm{~J}\left(M_{L}=1.41\right)$.

The next two blasts from the longwall face were performed during the start-up period (when the longwall face advance equalled about 15 and $30 \mathrm{~m}$ ). The blastholes deviated from the longwall face to the north-west and south-west at an angle of about 20 . 


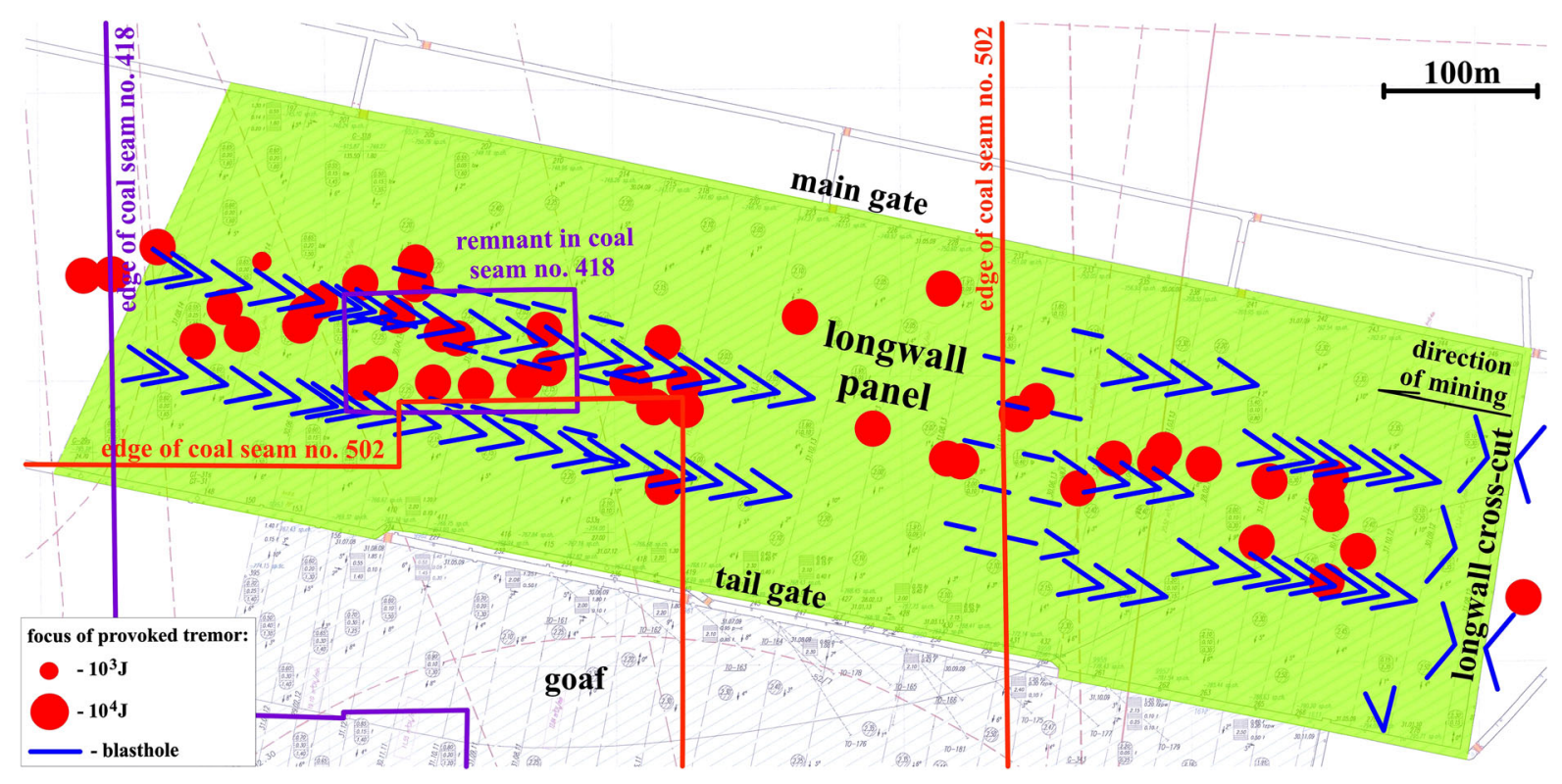

Figure 2

Map of the longwall panel in coal seam no. 506 with blastholes and the foci of provoked tremors

Other parameters were the same as in the first blast, but because of methane hazard, in the second blast one pair of blastholes was moved to the tail gate, to fresh airflow, and the inclination of these blastholes was raised upwards to an angle of 60 to the horizon. Two direct tremors were provoked due to these blasts and their energy equalled $6 \times 10^{4} \mathrm{~J}\left(M_{L}=1.57\right)$ and $4 \times 10^{4} \mathrm{~J}\left(M_{L}=1.47\right)$.

For the next 8 blasts (from 4 to 11), blastholes were drilled only from the longwall face, with the parameters outlined previously. Long-hole destress blasting was performed up to $30 \mathrm{~m}$ of longwall face advance. The energy of the provoked tremors ranged from $3 \times 10^{4} \mathrm{~J} \quad\left(M_{L}=1.41\right) \quad$ to $8 \times 10^{4} \mathrm{~J}$ $\left(M_{L}=1.63\right)$.

Because of seismic activity, concentrated ahead of the longwall face, near the edge of coal seam no. 502 (lying about 60-82 $\mathrm{m}$ above coal seam no. 506), in the next 3 blasts (12-14), another pair of blastholes was added. The blastholes deviated from the longwall face to the north-west and south-west at an angle of about 70 . They were $45 \mathrm{~m}$ long and inclined upwards at an angle of 45 to the horizon. Each time $432 \mathrm{~kg}$ of explosives were loaded into 6 blastholes $(72 \mathrm{~kg}$ per blasthole). Only direct tremors were provoked, with the energy of $8 \times 10^{4} \mathrm{~J}\left(M_{L}=1.63\right)$ and twice $4 \times 10^{4} \mathrm{~J}\left(M_{L}=1.47\right)$.

When the longwall face was in closest vicinity to the edge of coal seam no. 502, the parameters of the following 5 blasts (from 15 to 19) were modified once more. Each time three blastholes were drilled from the longwall face, and they were lengthened to 60-65 $\mathrm{m}$, and their inclination was raised to an angle of 60-70 to the horizon. During blasts nos. 15 and 16, $72 \mathrm{~kg}$ of explosives were fired in each blasthole. The column of the explosive material was located in the first 11-m-thick layer of sandstone, lying at a distance of about $39 \mathrm{~m}$ above coal seam no. 506. The energy of the tremors provoked directly equalled $7 \times 10^{4} \mathrm{~J}$ $\left(M_{L}=1.60\right)$ and $2 \times 10^{4} \mathrm{~J}\left(M_{L}=1.32\right)$. Two aftershocks occurred after the second blast of $8 \times 10^{2} \mathrm{~J}$ $\left(M_{L}=0.58\right)$ and $8 \times 10^{3} \mathrm{~J}\left(M_{L}=1.11\right)$. The mass of explosives was then raised to $144 \mathrm{~kg}$ per blasthole (blasts nos. 17-19). The column of the explosives occupied nearly $29 \mathrm{~m}$ of each blasthole. The tremors were provoked directly and had the energy of $2 \times 10^{4} \mathrm{~J}\left(M_{L}=1.32\right), 4 \times 10^{4} \mathrm{~J}\left(M_{L}=1.47\right)$ and $1 \times 10^{4} \mathrm{~J}\left(M_{L}=1.16\right)$.

Because of the fact that rock mass in the area of the longwall panel was destressed by the earlier 
extraction of both coal seams no. 418 and 502, and the small effect of blast no. 19 and the observed low level of rockburst hazard, the long-hole destress blasting from the longwall face was suspended. It was resumed when the longwall face was approaching the area where both the remnant of coal seam no. 418 and the edge of the coal seam no. 502 existed. The longhole destress blasting was executed regularly, every $30 \mathrm{~m}$ of longwall face advance.

Four blastholes, grouped in two pairs were drilled each time. In each pair, one blasthole deviated from the longwall face to the north-west, and the second to the south-west at an angle of approximately 70 . The length of the blastholes equalled $65 \mathrm{~m}$, and they were inclined upwards at an angle of 60 to the horizon, and $96 \mathrm{~kg}$ of explosives were loaded to each blasthole. During blasts nos. 20-25 each time $384 \mathrm{~kg}$ of explosives were fired. The energy of the tremors provoked directly was between $3 \times 10^{4} \mathrm{~J}\left(M_{L}=\right.$ $1.41)$ and $5 \times 10^{4} \mathrm{~J} \quad\left(M_{L}=1.53\right)$. Seismograms recorded directly after one of the long-hole destress blasts from the longwall face are shown in Fig. 3. After blasts nos. 20 and 23 aftershocks occurred (named 20a and 23a) with the energy of $7 \times 10^{4} \mathrm{~J}$ $\left(M_{L}=1.60\right)$ and $3 \times 10^{4} \mathrm{~J}\left(M_{L}=1.41\right)$, respectively.
After blast no. 25 two aftershocks occurred with the energy of $3 \times 10^{4} \mathrm{~J}\left(M_{L}=1.41\right)$-named $25 \mathrm{a}$-and $8 \times 10^{2} \mathrm{~J}\left(M_{L}=0.58\right)$.

Because of the high stress level in the rock mass and due to the presence of both the remnant of coal seam no. 418 and the edge of the coal seam no. 502, additional blasts, between those executed periodically, were planned. Blastholes were drilled perpendicularly to the longwall face, and they were $65 \mathrm{~m}$ long and inclined upwards at an angle of 60 to the horizon. The number of blastholes was variable, equalling 3 (blasts nos. 28, 30, 32, 34), 2 (blasts nos. 26,38 ), or 1 (blast no. 36). Only during blast no. 26 , was $96 \mathrm{~kg}$ of explosives loaded to each blasthole. In other cases, $120 \mathrm{~kg}$ of explosives per blasthole were loaded. The seismic energy of the directly provoked tremors ranged from $7 \times 10^{3} \mathrm{~J} \quad\left(M_{L}=1.08\right)$ to $5 \times 10^{4} \mathrm{~J}\left(M_{L}=1.53\right)$.

Because of the high stress level in the rock mass and due to the presence of both the remnant of coal seam no. 418 and the edge of the coal seam no. 502, the mass of the explosives during cyclic blasts (nos. $27,29,31,33,35,37,39,41-47$ ) increased as well. In total $480 \mathrm{~kg}$ of explosives were fired every time. The energy of the directly provoked tremors ranged

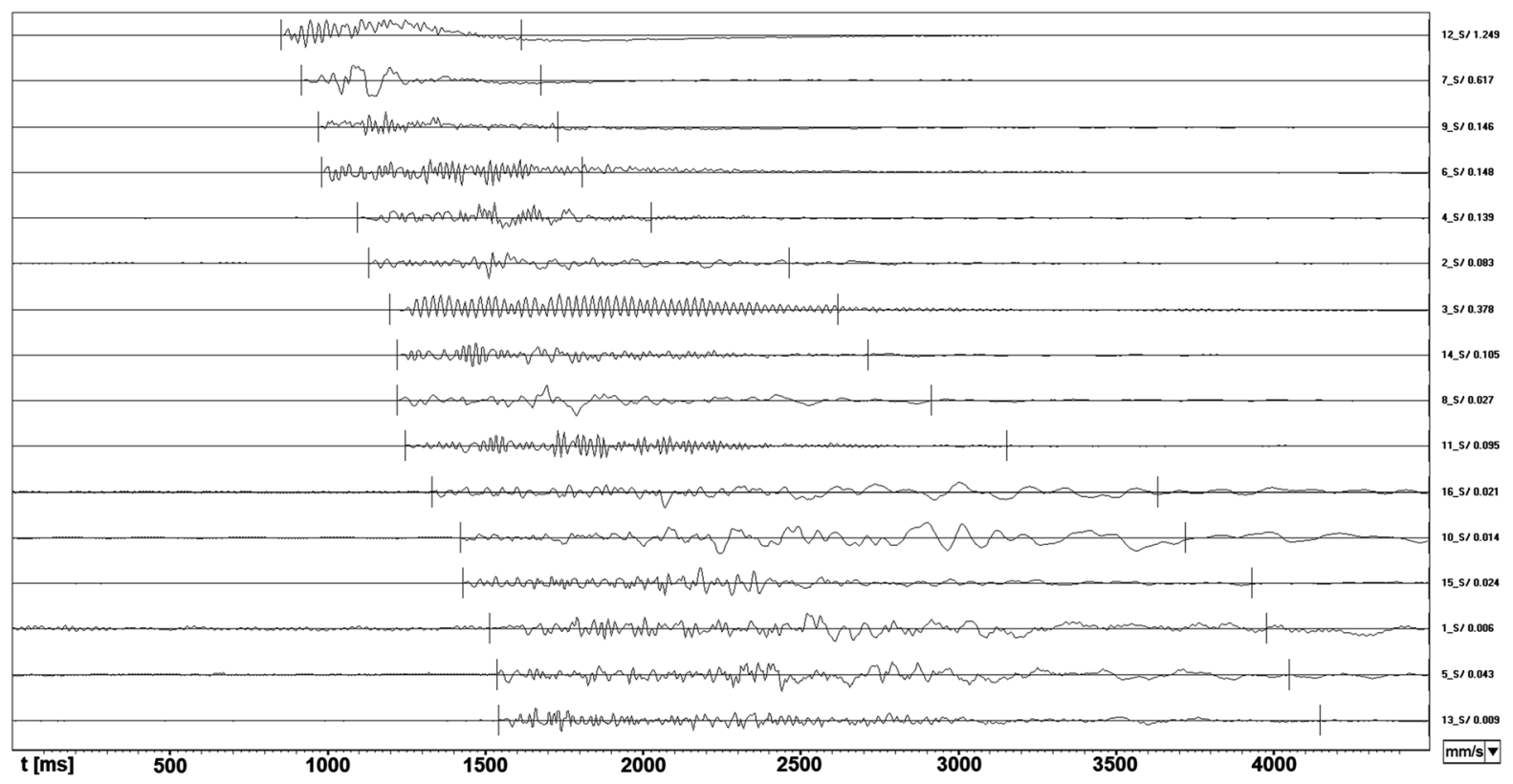

Figure 3

Seismograms recorded directly after one of the long-hole destress blasts from the longwall face 
from $3 \times 10^{4} \mathrm{~J} \quad\left(M_{L}=1.41\right) \quad$ to $\quad 8 \times 10^{4} \mathrm{~J}$ $\left(M_{L}=1.63\right)$.

The seismic source parameters of the tremors provoked by long-hole destress blasting during the longwall mining of coal seam no. 506 were calculated.

\section{Seismic Source Parameters}

Seismic source parameters characterize the focus of a tremor. In the beginning, these parameters were determined for natural earthquakes, but they were adopted for mine tremors (Gibowicz and Kijko 1994). Seismic source parameters are calculated based on the records from seismic stations. The squared power spectra of velocity $V(f)$ and displacement $D(f)$ are integrated in the frequency domain, to calculate parameters $J$ and $K$ (Andrews 1986; Snoke 1987; Mendecki 1997; Kwiatek et al. 2016):

$$
\begin{aligned}
& J=2 \int_{0}^{\infty} V^{2}(f) d f \\
& K=2 \int_{0}^{\infty} D^{2}(f) d f
\end{aligned}
$$

where $f$ is the frequency.

The above-mentioned calculations are made for finite frequency limits $f_{1}$ and $f_{2}$, so parameters $J$ and $K$ are underestimated, and they must be corrected (Mendecki 1997). The low frequency limit is usually taken as a reciprocal of the duration time of the signal for the Fourier transform. The upper limit may be defined e.g. by the Nyquist frequency, the sensor or system response, or noise characteristics (Wojtecki et al. 2017b). On the basis of parameters $J$ and $K$, the two elementary seismic source parameters, called low-frequency spectral level $\Omega_{o}$ and corner frequency $f_{o}$, can be determined. They are calculated according to the formulas presented by (Andrews 1986; Snoke 1987):

$$
\Omega_{o}=2\left(\frac{K^{3}}{J}\right)^{\frac{1}{4}}
$$

$$
f_{o}=\frac{1}{2 \pi}\left(\frac{J}{K}\right)^{\frac{1}{2}}
$$

The scalar seismic moment $M_{o}$ is a measure of the size of a tremor. It can be calculated by the following equation (Aki and Richards 1980; McGarr et al. 1989; Gibowicz and Kijko 1994; Trifu et al. 1995):

$$
M_{o}=\frac{4 \pi \rho V_{c}^{3} R \Omega_{o}}{R_{c} F_{c} S_{c}}
$$

In the previous formula, $\rho$ means the density, and $V_{c}$ means the P-or S-wave velocity in the source area. The distance between the source and the receiver is marked by $R$. The other parameters, i.e. correction for the radiation, free-surface effect and site, are marked as $R_{c}, F_{c}, S_{c}$, respectively. The scalar seismic moment of relatively strong events induced in the mines varies greatly (Cichowicz 1981; McGarr et al. 1989; Trifu et al. 1995; Dubiński et al. 1996; Orlecka-Sikora et al. 2012; Lizurek et al. 2015; Rudziński et al. 2016). Calculation of the scalar seismic moment $M_{o}$ for the tremors provoked by blasting is even rare. The seismic moment of tremors provoked by blasts (400-600 kg of explosives) in Indian hard coal mines changed from $1.2 \times 10^{8} \mathrm{Nm}$ to $2.8 \times 10^{10} \mathrm{Nm}$ (Srinivasan et al. 2005). Firing a $563 \mathrm{~kg}$ of explosives provoked a tremor with $M_{O}=1.2 \times 10^{8} \mathrm{Nm}$ (Srinivasan et al. 2005). An analogous observation was done for the effects of the long-hole destress blasting in roof rocks and blasting for roof falling in one of the Polish hard coal mines. The scalar seismic moment $M_{O}$ of tremors provoked by the long-hole destress blasting ranged between $7.57 \times 10^{9} \mathrm{Nm}$ and $8.35 \times 10^{11} \mathrm{Nm}$ (Wojtecki et al. 2017a; b). These tremors were provoked by the firing of $42-576 \mathrm{~kg}$ of explosives (Wojtecki et al. 2017a; b). The scalar seismic moment $M_{O}$ of tremors provoked by the blasting for roof falling equalled from $1.44 \times 10^{10} \mathrm{Nm}$ to $1.47 \times 10^{11} \mathrm{Nm}$ (Wojtecki et al. 2017a, 2019). The mass of explosives fired was between 24 and $120 \mathrm{~kg}$ (Wojtecki et al. 2017a, 2019).

The scalar seismic moment $M_{o}$ and the moment magnitude $M_{w}$ are linked by the following relation (Hanks and Kanamori 1979): 


$$
M_{w}=\frac{2}{3} \log _{10} M_{o}-6
$$

The moment magnitude $M_{w}$ is usually smaller than the local magnitude $M_{L}$ (Baruah et al. 2012; Lizurek et al. 2015). The moment magnitude $M_{w}$ equalled from 0.45 to 1.78 for tremors provoked by the long-hole destress blasting in roof rocks of a coal seam (Wojtecki et al. 2017a, b), and from 0.67 to 1.29 for tremors provoked by the blasting for roof falling (Wojtecki et al. 2017a, 2019).

The seismic energy $E_{c}$ describes the wave energy emitted from a seismic source. The mean average radiation coefficient $\left\langle R_{c}\right\rangle$ has been captured to determine this parameter (Gibowicz and Kijko 1994):

$$
E_{c}=4 \pi \rho V_{c}\left\langle R_{c}\right\rangle^{2}\left(\frac{R}{F_{c} R_{c}}\right)^{2} J
$$

It can be calculated with the use of both P- and S-waves. This way of calculation differs from the numerical integration method described previously. The seismic energy $E_{c}$ of tremors provoked by the long-hole destress blasting in roof rocks of a coal seam equalled from $3.7 \times 10^{3} \mathrm{~J}$ to $8.4 \times 10^{5} \mathrm{~J}$ (Wojtecki et al. 2017a; b). The seismic energy $E_{c}$ of tremors provoked by the blasting for roof falling ranged between $7.4 \times 10^{3} \mathrm{~J}$ and $9.8 \times 10^{4} \mathrm{~J}(\mathrm{Wo}-$ jtecki et al. 2017a, 2019).

The source radius $r$ can also be determined from the records of seismic waves, and it is proportional to the S-wave velocity $V_{s}$ and inversely proportional to the corner frequency $f_{o}$ :

$$
r=\frac{c V_{s}}{2 \pi f_{o}}
$$

The value of constant $c$ depends on the assumed model. It equals 2.34 (Brune 1970) or 1.32 (Madariaga 1976). The source radius $r$ ranged between 20.1 and $65.8 \mathrm{~m}$ for tremors provoked by the long-hole destress blasting in roof rocks (Wojtecki et al. 2017a, b), and from 30.2 to $64.5 \mathrm{~m}$ for tremors provoked by the blasting for roof falling (Wojtecki et al. 2017a, 2019).

The difference in stress levels before and after the tremor can be described by the stress drop $\Delta \sigma$ (Aki and Richards 1980; McGarr et al. 1989; Trifu et al. 1995):

$$
\Delta \sigma=\frac{7}{16} \frac{M_{o}}{r^{3}}
$$

It depends on the source radius $r$, calculated according to the assumed source model. Stress drop in seismology is estimated for some simple fault models with assumed geomechanical parameters and source time functions. Then, in a physical sense, it describes the difference (drop) between shear stress before and after a tremor during the slip on the fault. If stress drop is only estimated from seismogram frequency spectra, it may be highly uncertain (Stein and Wysession 2003), but it is reasonable to assume that it describes the state of rock mass after the induced tremor near the focus. The stress drop in the foci of tremors provoked by blasting in Indian hard coal mines equalled 3-556 bar (Srinivasan et al. $2005)$, i.e. from $3 \times 10^{5} \mathrm{~Pa}$ to $5.56 \times 10^{7} \mathrm{~Pa}$. In the foci of tremors provoked by the long-hole destress blasting in roof rocks of a coal seam the stress drop $\Delta \sigma$ was between $4.75 \times 10^{5} \mathrm{~Pa}$ to $3.05 \times 10^{6} \mathrm{~Pa}$ (Wojtecki et al. 2017a, b). The stress drop $\Delta \sigma$ in the foci of tremors provoked by the blasting for roof falling ranged from $3.37 \times 10^{5} \mathrm{~Pa}$ to $1.19 \times 10^{6} \mathrm{~Pa}$ (Wojtecki et al. 2017a, 2019).

The radiated energy per unit area per unit slip is described by the apparent stress $\sigma_{a}$ (Aki and Richards 1980; McGarr et al. 1989; Trifu et al. 1995):

$$
\sigma_{a}=\rho V_{s}^{2} \frac{E}{M_{o}}=\eta<\sigma>
$$

where $\eta$ is the seismic efficiency, and $\langle\sigma\rangle$ is the average shear stress, which is proportional to the seismic drop. It should be noticed that the apparent stress $\sigma_{a}$ does not reflect the actual stress drop. The apparent stress varied from $8.22 \times 10^{3} \mathrm{~J} / \mathrm{m}^{3}$ to $7.76 \times 10^{4} \mathrm{~J} / \mathrm{m}^{3}$ for tremors provoked by the longhole destress blasting in roof rocks of coal seams (Wojtecki et al. 2017a, b), and from $6.1 \times 10^{3} \mathrm{~J} / \mathrm{m}^{3}$ to $2.92 \times 10^{4} \mathrm{~J} / \mathrm{m}^{3}$ for tremors provoked by the blasting for roof falling (Wojtecki et al. 2017a, 2019).

A seismic event can be considered as a sudden inelastic deformation within a given volume of rocks that radiates seismic waves (Mendecki 1997). This inelastic deformation can be described by two parameters, i. e. source volume and apparent volume (Mendecki 1997). The source volume $V_{s}$ is defined as 
the ratio of the seismic moment to stress drop (Mendecki 1997):

$$
V_{s}=\frac{M_{o}}{\Delta \sigma}
$$

The seismic volume can be calculated for tremors provoked by blasting as well. It equalled $7.8 \times 10^{5} \mathrm{~m}^{3}$ when a $150 \mathrm{~kg}$ charge was fired in 6 blastholes, and $1.5 \times 10^{5} \mathrm{~m}^{3}$ when a $250 \mathrm{~kg}$ charge was fired in 2 blastholes (Mendecki 1997). The first blasting can be considered as more successful than the second one since it induced an inelastic deformation over a larger volume (Mendecki 1997). The source volume was also calculated for tremors provoked by blasting for roof falling in one of the hard coal mines (Wojtecki et al. 2019). It equalled $8 \times 10^{4} \mathrm{~m}^{3}$ when a $24 \mathrm{~kg}$ charge was fired, $4.4 \times 10^{5} \mathrm{~m}^{3}$ when a $72 \mathrm{~kg}$ charge was fired, and $1.4 \times 10^{5} \mathrm{~m}^{3}$ when a $120 \mathrm{~kg}$ charge was fired (Wojtecki et al. 2019).

Since apparent stress $\sigma_{a}$ scales with stress drop, and since there is less model dependence in determining the apparent stress than there is in determining corner frequency cubed dependent static stress drop, and because, in general, the stress drop is greater than or equal double apparent stress, thus one can define the apparent volume $V_{a}$ as follows (Mendecki 1993, 1997):

$$
V_{a}=\frac{M_{o}}{2 \sigma_{a}}
$$

The apparent volume for a given seismic event measures the volume of rock with the coseismic inelastic strain (Mendecki 1997). It was calculated for tremors provoked by blasting for roof falling in one of the hard coal mines, and it equalled $1.3 \times 10^{6} \mathrm{~m}^{3}$ when a $24 \mathrm{~kg}$ charge was fired, $1.05 \times 10^{7} \mathrm{~m}^{3}$ when a $72 \mathrm{~kg}$ charge was fired, and $4 \times 10^{6} \mathrm{~m}^{3}$ when a $120 \mathrm{~kg}$ charge was fired (Wojtecki et al. 2019).

\section{Results}

The seismic source parameters were calculated on the basis of records registered by the mine seismological network, and via the FOCI software (Kwiatek et al. 2016), assuming a far-field point source model.
Calculations were made individually for seismic stations after each destress blasting. Because of the near-field effect, seismograms recorded by the two DLM-2001 geophones, installed in the longwall gates were not taken to calculate the seismic source parameters. Only records from the seismic sensors located at least about $600 \mathrm{~m}$ or at larger distances from the seismic sources, and undisturbed were taken into account. Only two seismic sensors were closer than $1 \mathrm{~km}$, and the maximum source-receiver distance was about $4.1 \mathrm{~km}$. An average distance between the seismic sources and included seismic receivers equalled about $2200 \mathrm{~m}$. The P-waves were marked manually on seismograms. The appropriate parts of the seismogram were then transformed by the Fast Fourier Transform (FFT). The low-frequency spectral level $\Omega_{o}$ and the corner frequency $f_{o}$ were estimated for each spectrum of the P-waves. Next, the scalar seismic moment $M_{o}$, the moment magnitude $M_{w}$, the seismic energy $E_{p}$, the source radius $r$ (according to Brune's source model), the stress drop $\Delta \sigma$, and the apparent stress $\sigma_{a}$ were calculated. Determined seismic source parameters were then averaged for each provoked tremor separately. Due to the average values, the formulas presented above cannot be directly applied. The source volume $V_{s}$ and the apparent volume $V_{a}$ were calculated on the basis of averaged values of the scalar seismic moment $M_{o}$, the stress drop $\Delta \sigma$, and the apparent stress $\sigma_{a}$. The obtained seismic source parameters of the directly provoked tremors are shown in Table 1.

Seismic source parameters presented in Table 1 have been calculated for tremors provoked by blasts with changeable parameters (number of blastholes: 1-6, the mass of explosives: $120-480 \mathrm{~kg}$, length of blastholes: $45-65 \mathrm{~m}$, inclination of blastholes: $45^{\circ}-$ $70^{\circ}$ to the horizon etc.) and under variable stress conditions. The low-frequency spectral level $\Omega_{o}$ varies from $0.25 \times 10^{-8}$ to $5.91 \times 10^{-8}$ (mean $\left.1.87 \times 10^{-8}\right)$. The corner frequency $f_{o}$ is between 15.52 and $31.39 \mathrm{~Hz}$ (mean $24.68 \mathrm{~Hz}$ ). The scalar seismic moment $M_{o}$ is from $1.23 \times 10^{11} \mathrm{Nm}$ to $7.80 \times 10^{11} \mathrm{Nm} \quad\left(\right.$ mean $\left.2.51 \times 10^{11} \mathrm{Nm}\right)$. The moment magnitude $M_{w}$ varies from 1.14 to 1.86 (mean 1.47). The seismic energy calculated for P-waves $E_{p}$ ranges from $1.03 \times 10^{4} \mathrm{~J}$ to $3.5 \times 10^{5} \mathrm{~J}$ (mean $1.2 \times 10^{5} \mathrm{~J}$ ). The source radius $r$ is from 27.2 
Table 1

The seismic source parameters of tremors provoked by the long-hole destress blasting executed during mining of coal seam no. 506

\begin{tabular}{|c|c|c|c|c|c|c|c|c|c|c|c|c|}
\hline \multirow[t]{2}{*}{ No. } & \multirow{2}{*}{$\begin{array}{l}\text { Mass of } \\
\text { explosives }[\mathrm{kg}]\end{array}$} & \multirow[t]{2}{*}{$M_{L}$} & \multicolumn{10}{|c|}{ Seismic source parameters } \\
\hline & & & $\Omega_{o} \times 10^{-8}$ & $\begin{array}{l}f_{o} \\
{[\mathrm{~Hz}]}\end{array}$ & $\begin{array}{l}M_{o} \times 10^{11} \\
{[\mathrm{Nm}]}\end{array}$ & $M_{w}$ & $\begin{array}{l}E_{p} \times 10^{4} \\
{[\mathrm{~J}]}\end{array}$ & $r[\mathrm{~m}]$ & $\begin{array}{l}\Delta \sigma \times 10^{6} \\
{[\mathrm{~Pa}]}\end{array}$ & $\begin{array}{l}\sigma_{a} \times 10^{4}[\mathrm{~J} / \\
\left.\mathrm{m}^{3}\right]\end{array}$ & $\begin{array}{l}V_{s} \times 10^{5} \\
{\left[\mathrm{~m}^{3}\right]}\end{array}$ & $\begin{array}{l}V_{a} \times 10^{7} \\
{\left[\mathrm{~m}^{3}\right]}\end{array}$ \\
\hline 1 & 288 & 1.41 & 0.66 & 25.71 & 1.18 & 1.30 & 3.1 & 38.7 & 1.34 & 0.50 & 0.88 & 1.18 \\
\hline 2 & 288 & 1.57 & 0.88 & 22.83 & 1.47 & 1.35 & 7.9 & 41.9 & 1.93 & 0.72 & 0.76 & 1.02 \\
\hline 3 & 288 & 1.47 & 0.43 & 29.39 & 0.96 & 1.24 & 6.2 & 33.1 & 2.38 & 0.89 & 0.40 & 0.54 \\
\hline 4 & 288 & 1.53 & 1.02 & 24.92 & 1.58 & 1.42 & 8.2 & 38.4 & 2.47 & 0.93 & 0.64 & 0.85 \\
\hline 5 & 288 & 1.41 & 1.12 & 26.34 & 1.23 & 1.25 & 10.7 & 32.9 & 2.69 & 1.01 & 0.46 & 0.61 \\
\hline 6 & 288 & 1.63 & 1.39 & 25.42 & 2.14 & 1.51 & 16.1 & 35.1 & 3.38 & 1.26 & 0.63 & 0.85 \\
\hline 7 & 288 & 1.53 & 1.45 & 24.61 & 1.61 & 1.42 & 8.8 & 37.8 & 2.52 & 0.94 & 0.64 & 0.86 \\
\hline 8 & 288 & 1.60 & 2.95 & 24.78 & 3.14 & 1.43 & 17.4 & 45.9 & 2.77 & 1.04 & 1.13 & 1.51 \\
\hline 9 & 288 & 1.60 & 1.57 & 24.28 & 1.94 & 1.49 & 15.3 & 39.7 & 3.70 & 1.38 & 0.52 & 0.70 \\
\hline 10 & 288 & 1.63 & 1.86 & 22.22 & 2.81 & 1.44 & 25.9 & 46.8 & 2.90 & 1.09 & 0.97 & 1.29 \\
\hline 11 & 288 & 1.63 & 2.45 & 20.61 & 2.54 & 1.49 & 16.8 & 47.5 & 2.84 & 1.06 & 0.89 & 1.20 \\
\hline 12 & 432 & 1.63 & 2.35 & 19.32 & 3.03 & 1.57 & 14.1 & 52.5 & 2.36 & 0.88 & 1.28 & 1.72 \\
\hline 13 & 432 & 1.47 & 0.58 & 28.45 & 1.23 & 1.27 & 7.9 & 29.3 & 2.29 & 0.86 & 0.54 & 0.72 \\
\hline 14 & 432 & 1.47 & 0.79 & 31.38 & 2.00 & 1.39 & 6.4 & 31.7 & 3.06 & 1.15 & 0.65 & 0.87 \\
\hline 15 & 288 & 1.60 & 2.84 & 20.27 & 3.27 & 1.60 & 17.9 & 44.4 & 2.19 & 0.82 & 1.49 & 1.99 \\
\hline 16 & 288 & 1.32 & 0.69 & 29.75 & 1.33 & 1.35 & 4.6 & 30.8 & 2.27 & 0.85 & 0.59 & 0.78 \\
\hline 17 & 432 & 1.32 & 0.62 & 26.11 & 1.16 & 1.33 & 4.8 & 36.4 & 2.12 & 0.79 & 0.55 & 0.73 \\
\hline 18 & 432 & 1.47 & 2.26 & 29.58 & 2.43 & 1.41 & 13.0 & 42.9 & 3.41 & 1.28 & 0.71 & 0.95 \\
\hline 19 & 432 & 1.16 & 0.79 & 31.39 & 1.36 & 1.36 & 7.1 & 27.2 & 2.79 & 1.05 & 0.49 & 0.65 \\
\hline 20 & 384 & 1.41 & 2.69 & 25.34 & 2.41 & 1.42 & 11.9 & 37.5 & 2.01 & 0.75 & 1.20 & 1.61 \\
\hline 21 & 384 & 1.53 & 1.23 & 30.28 & 2.82 & 1.55 & 17.6 & 42.9 & 6.14 & 2.30 & 0.46 & 0.61 \\
\hline 22 & 384 & 1.47 & 0.76 & 29.28 & 1.39 & 1.40 & 8.3 & 31.1 & 3.22 & 1.21 & 0.43 & 0.57 \\
\hline 23 & 384 & 1.47 & 1.40 & 28.51 & 1.57 & 1.37 & 7.9 & 41.5 & 2.89 & 1.08 & 0.54 & 0.72 \\
\hline 24 & 384 & 1.41 & 0.51 & 26.55 & 1.27 & 1.35 & 3.8 & 32.3 & 1.65 & 0.62 & 0.77 & 1.02 \\
\hline 25 & 384 & 1.53 & 1.82 & 26.09 & 2.32 & 1.50 & 15.8 & 41.4 & 3.70 & 1.39 & 0.63 & 0.84 \\
\hline 26 & 192 & 1.32 & 0.50 & 29.91 & 1.01 & 1.28 & 3.1 & 30.2 & 1.80 & 0.70 & 0.56 & 0.72 \\
\hline 27 & 480 & 1.63 & 5.71 & 15.52 & 6.91 & 1.86 & 25.2 & 54.4 & 1.97 & 0.74 & 3.51 & 4.67 \\
\hline 28 & 360 & 1.47 & 1.84 & 25.27 & 2.02 & 1.41 & 7.4 & 38.6 & 2.11 & 0.79 & 0.96 & 1.28 \\
\hline 29 & 480 & 1.53 & 1.59 & 26.03 & 2.11 & 1.49 & 14.0 & 43.2 & 3.25 & 1.22 & 0.65 & 0.87 \\
\hline 30 & 360 & 1.47 & 0.80 & 25.49 & 1.39 & 1.40 & 4.8 & 33.5 & 1.84 & 0.69 & 0.76 & 1.01 \\
\hline 31 & 480 & 1.63 & 5.91 & 20.92 & 7.29 & 1.78 & 35.0 & 53.3 & 4.34 & 1.63 & 1.68 & 2.24 \\
\hline 32 & 360 & 1.41 & 1.20 & 24.9 & 1.82 & 1.41 & 4.9 & 44.5 & 2.22 & 0.83 & 0.82 & 1.10 \\
\hline 33 & 480 & 1.53 & 0.86 & 24.85 & 1.83 & 1.46 & 19.1 & 44.1 & 4.84 & 1.81 & 0.38 & 0.51 \\
\hline 34 & 360 & 1.53 & 2.50 & 28.3 & 2.31 & 1.46 & 6.5 & 40.2 & 2.53 & 0.95 & 0.91 & 1.22 \\
\hline 35 & 480 & 1.57 & 0.92 & 20.39 & 2.67 & 1.48 & 7.3 & 42.5 & 1.19 & 0.44 & 2.24 & 3.03 \\
\hline 36 & 120 & 1.16 & 0.25 & 29.63 & 0.60 & 1.14 & 1.0 & 32.0 & 1.15 & 0.43 & 0.52 & 0.70 \\
\hline 37 & 480 & 1.41 & 5.12 & 19.23 & 3.59 & 1.63 & 13.6 & 43.7 & 1.70 & 0.64 & 2.11 & 2.80 \\
\hline 38 & 240 & 1.47 & 1.62 & 24.05 & 2.26 & 1.47 & 9.0 & 39.3 & 2.28 & 0.86 & 0.99 & 1.31 \\
\hline 39 & 480 & 1.57 & 1.20 & 18.74 & 2.87 & 1.58 & 8.2 & 45.9 & 1.39 & 0.52 & 2.07 & 2.76 \\
\hline 40 & 120 & 1.08 & 1.05 & 26.98 & 1.01 & 1.24 & 2.6 & 39.3 & 1.36 & 0.51 & 0.74 & 0.99 \\
\hline 41 & 480 & 1.47 & 1.53 & 22.34 & 2.00 & 1.47 & 7.6 & 47.7 & 2.23 & 0.83 & 0.90 & 1.20 \\
\hline 42 & 480 & 1.60 & 5.15 & 21.81 & 7.80 & 1.76 & 27.8 & 51.7 & 3.69 & 1.38 & 2.11 & 2.83 \\
\hline 43 & 480 & 1.53 & 5.11 & 21.13 & 4.61 & 1.72 & 22.1 & 42.4 & 2.98 & 1.11 & 1.55 & 2.08 \\
\hline 44 & 480 & 1.41 & 1.61 & 21.09 & 3.19 & 1.64 & 13.3 & 39.8 & 2.23 & 0.83 & 1.43 & 1.92 \\
\hline 45 & 480 & 1.57 & 4.27 & 18.82 & 4.83 & 1.75 & 22.2 & 44.4 & 2.33 & 0.87 & 2.07 & 2.78 \\
\hline 46 & 480 & 1.41 & 2.12 & 20.87 & 5.00 & 1.72 & 17.7 & 48.4 & 2.81 & 1.05 & 1.78 & 2.38 \\
\hline 47 & 480 & 1.41 & 1.94 & 20.35 & 3.69 & 1.62 & 15.3 & 41.8 & 1.96 & 0.73 & 1.88 & 2.53 \\
\hline
\end{tabular}


Table 2

Average values of the seismic source parameters according to the mass of fired explosives

\begin{tabular}{|c|c|c|c|c|c|c|c|c|c|c|c|}
\hline \multirow[t]{2}{*}{ No. } & \multirow{2}{*}{$\begin{array}{l}\text { Mass of explosives } \\
{[\mathrm{kg}]}\end{array}$} & \multicolumn{10}{|c|}{ Seismic source parameters } \\
\hline & & $\Omega_{o} \times 10^{-8}$ & $\begin{array}{l}f_{o} \\
{[\mathrm{~Hz}]}\end{array}$ & $\begin{array}{l}M_{o} \times 10^{11} \\
{[\mathrm{Nm}]}\end{array}$ & $M_{w}$ & $\begin{array}{l}E_{p} \times 10^{4} \\
{[\mathrm{~J}]}\end{array}$ & $\begin{array}{l}r \\
{[\mathrm{~m}]}\end{array}$ & $\begin{array}{l}\Delta \sigma \times 10^{6} \\
{[\mathrm{~Pa}]}\end{array}$ & $\begin{array}{l}\sigma_{a} \times 10^{4}[\mathrm{~J} / \\
\left.\mathrm{m}^{3}\right]\end{array}$ & $\begin{array}{l}V_{s} \times 10^{5} \\
{\left[\mathrm{~m}^{3}\right]}\end{array}$ & $\begin{array}{l}V_{a} \times 10^{7} \\
{\left[\mathrm{~m}^{3}\right]}\end{array}$ \\
\hline 1 & 120 & 0.65 & 28.31 & 0.80 & 1.19 & 1.8 & 35.7 & 1.26 & 0.47 & 0.63 & 0.84 \\
\hline 2 & 288 & 1.48 & 24.70 & 1.84 & 1.41 & 12.2 & 39.5 & 2.57 & 0.96 & 0.77 & 1.03 \\
\hline 3 & 360 & 1.58 & 25.99 & 1.89 & 1.42 & 5.9 & 39.2 & 2.18 & 0.81 & 0.86 & 1.15 \\
\hline 4 & 384 & 1.40 & 27.68 & 1.96 & 1.43 & 10.9 & 37.8 & 3.27 & 1.22 & 0.67 & 0.90 \\
\hline 5 & 432 & 1.23 & 27.71 & 1.87 & 1.39 & 8.9 & 36.7 & 2.67 & 1.00 & 0.70 & 0.94 \\
\hline 6 & 480 & 3.07 & 20.86 & 4.17 & 1.64 & 17.7 & 45.6 & 2.64 & 0.99 & 1.74 & 2.33 \\
\hline 7 & $192^{\mathrm{a}}$ & 0.50 & 29.91 & 1.01 & 1.28 & 3.1 & 30.2 & 1.80 & 0.70 & 0.56 & 0.72 \\
\hline 8 & $240^{\mathrm{a}}$ & 1.62 & 24.05 & 2.26 & 1.47 & 9.0 & 39.3 & 2.28 & 0.86 & 0.99 & 1.31 \\
\hline
\end{tabular}

${ }^{\mathrm{a}}$ Seismic source parameters of tremors provoked by the single blast

Table 3

Seismic source parameters of tremors provoked by the long-hole destress blasting in the waiting time

\begin{tabular}{|c|c|c|c|c|c|c|c|c|c|c|c|}
\hline \multirow{2}{*}{\multicolumn{2}{|c|}{ No. $M_{L}$}} & \multicolumn{10}{|c|}{ Seismic source parameters } \\
\hline & & $\Omega_{o} \times 10^{-8}$ & $\begin{array}{l}f_{o} \\
{[\mathrm{~Hz}]}\end{array}$ & $\begin{array}{l}M_{o} \times 10^{11} \\
{[\mathrm{Nm}]}\end{array}$ & $M_{w}$ & $\begin{array}{l}E_{p} \times 10^{4} \\
{[\mathrm{~J}]}\end{array}$ & $r[\mathrm{~m}]$ & $\begin{array}{l}\Delta \sigma \times 10^{6} \\
{[\mathrm{~Pa}]}\end{array}$ & $\begin{array}{l}\sigma_{a} \times 10^{4}[\mathrm{~J} / \\
\left.\mathrm{m}^{3}\right]\end{array}$ & $\begin{array}{l}V_{s} \times 10^{5} \\
{\left[\mathrm{~m}^{3}\right]}\end{array}$ & $\begin{array}{l}V_{a} \times 10^{7} \\
{\left[\mathrm{~m}^{3}\right]}\end{array}$ \\
\hline $20 \mathrm{a}$ & 1.60 & 7.68 & 14.48 & 8.18 & 1.83 & 41.90 & 69.9 & 2.44 & 0.91 & 3.35 & 4.49 \\
\hline $23 \mathrm{a}$ & 1.41 & 1.10 & 21.84 & 1.71 & 1.42 & 5.80 & 38.1 & 1.41 & 0.52 & 1.21 & 1.64 \\
\hline $25 \mathrm{a}$ & 1.41 & 1.08 & 22.77 & 2.00 & 1.37 & 7.50 & 57.1 & 1.69 & 0.64 & 1.18 & 1.56 \\
\hline
\end{tabular}

to $54.4 \mathrm{~m}$ (mean $40.4 \mathrm{~m}$ ). The stress drop $\Delta \sigma$ varies from $1.15 \times 10^{6} \mathrm{~Pa}$ to $6.14 \times 10^{6} \mathrm{~Pa}$ (mean $2.58 \times 10^{6} \mathrm{~Pa}$ ). The apparent stress $\sigma_{a}$ is between $0.44 \times 10^{4} \mathrm{~J} / \mathrm{m}^{3}$ and $2.3 \times 10^{4} \mathrm{~J} / \mathrm{m}^{3}$ (mean $0.97 \cdot 10^{4} \mathrm{~J} / \mathrm{m}^{3}$ ). The source volume $V_{s}$ ranges between $3.78 \times 10^{4} \mathrm{~m}^{3}$ and $3.51 \times 10^{5} \mathrm{~m}^{3} \quad$ (mean $\left.1.04 \times 10^{5} \mathrm{~m}^{3}\right)$. The apparent volume $V_{a}$ varies from $5.06 \times 10^{6} \mathrm{~m}^{3}$ to $4.67 \times 10^{7} \mathrm{~m}^{3} \quad$ (mean $1.39 \times 10^{7} \mathrm{~m}^{3}$ ).

According to the mass of the used explosives, 6 groups of tremors have been distinguished. The average values of the seismic source parameters of the tremors provoked by firing 120, 288, 360, 384, 432 and $480 \mathrm{~kg}$ of explosives are presented in Table 2. The seismic source parameters of tremors provoked by the single blast, and with the use of 192 and $240 \mathrm{~kg}$ are shown in Table 1 and added into Table 2.
In the waiting time after blasts nos. 20, 23 and 25, every time an aftershock with seismic energy of the order of $10^{4} \mathrm{~J}$ occurred, named $20 \mathrm{a}, 23 \mathrm{a}$ and $25 \mathrm{a}$, $7 \times 10^{4} \mathrm{~J}\left(M_{L}=1.60\right), 3 \times 10^{4} \mathrm{~J}\left(M_{L}=1.41\right)$ and $3 \times 10^{4} \mathrm{~J}\left(M_{L}=1.41\right)$ respectively. These tremors occurred after blasts with identical parameters and under analogous geological and mining conditions. The seismic source parameters of these tremors are shown in Table 3.

The analysed spectral parameters were compared with the mass of fired explosives $(Q)$. Moreover, the results obtained in previous research were included. These results concerned described previously longhole destress blasts and blasts for roof falling, carried out in the same mine and with the use of the same type of explosive material, but for underground workings in different coal seams, nos. 504 and 507 (Wojtecki et al. 2017a, b, 2019). The correlations 
(a)

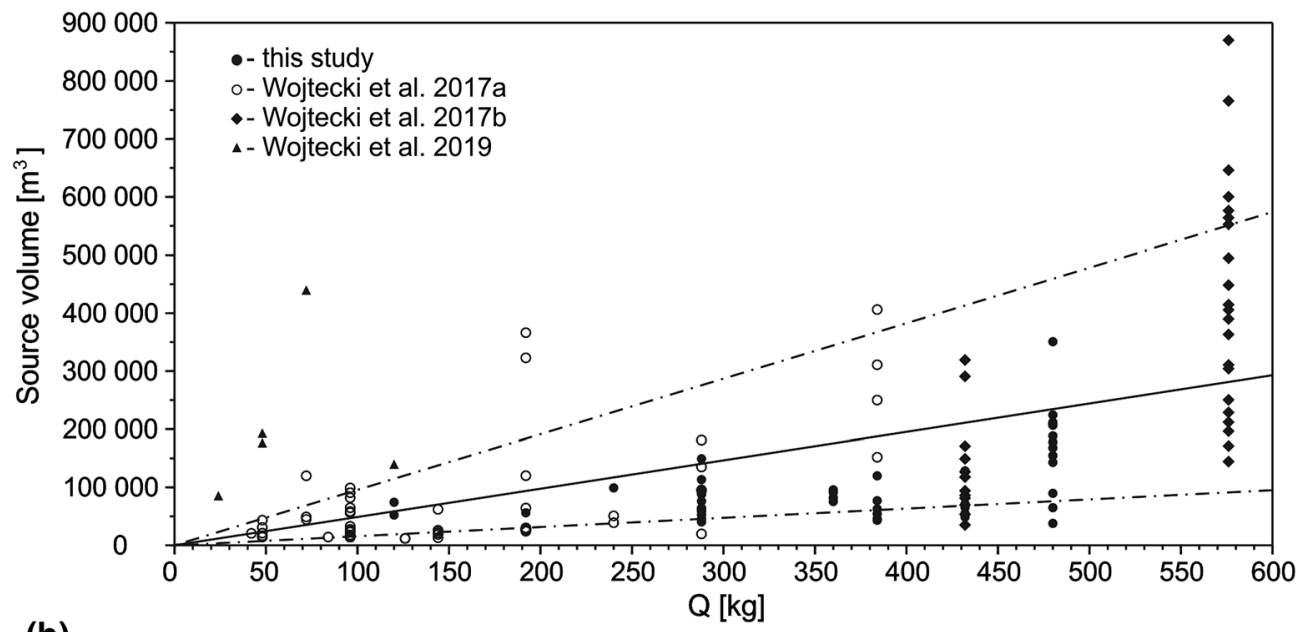

(b)

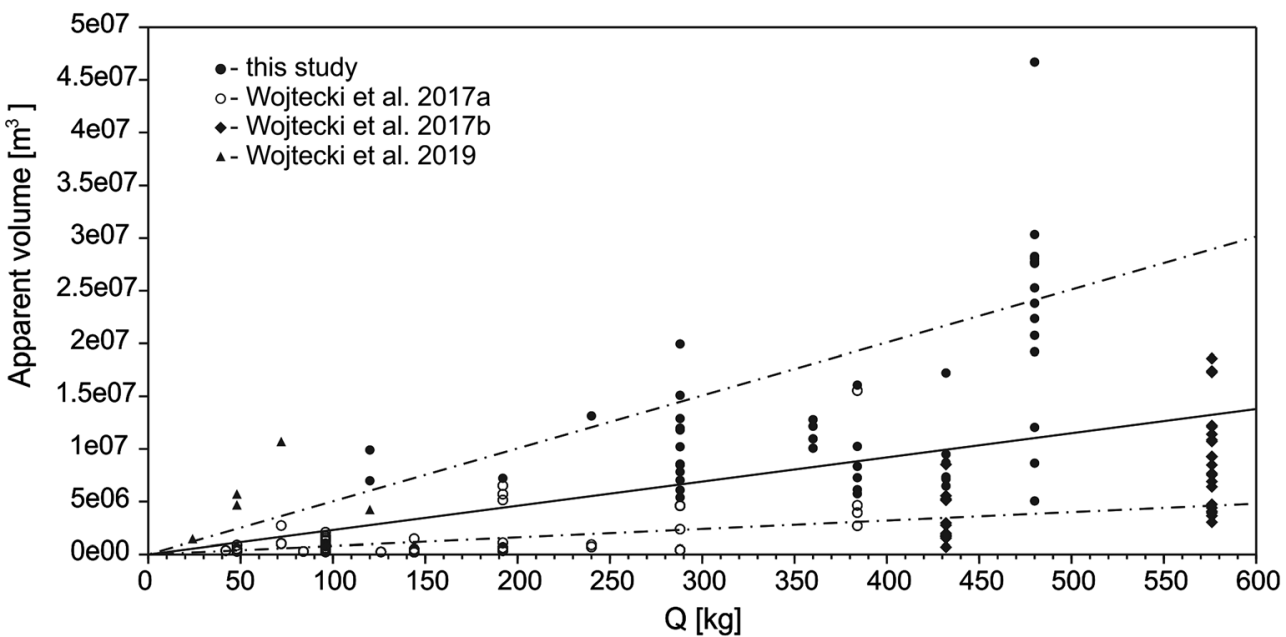

Figure 4

The relation between source volume and Q (a) and between apparent volume and Q (b)

between $Q$ and the calculated source volume $V_{s}$, and apparent volume $V_{a}$ were determined (Fig. $4 \mathrm{a}, \mathrm{b}$, respectively). Figure 5a, b show the relation between $Q$ and the stress drop and, as well as, between $Q$ and the stress drop multiplied by the focus surface, was determined respectively. Assuming the Brune's circular dislocation model (Brune 1970), the range of area destressed by blasting was determined for current data and data published in (Wojtecki et al. $2017 \mathrm{a}, \mathrm{b}, 2019)$, in $\left[\mathrm{Pa} \mathrm{m}^{2}=\mathrm{N}\right]$. It varies between $6.75 \times 10^{8} \mathrm{~Pa} \mathrm{~m}^{2}$ and $3.87 \times 10^{10} \mathrm{~Pa} \mathrm{~m}^{2}$ (mean $8.89 \times 10^{9} \mathrm{~Pa} \mathrm{~m}^{2}$ ).
The linear models were obtained using linear regression assuming free element as zero. The slope values for the models represents as follows: 488.14 (Fig. 4a); 22987.05 (Fig. 4b); 4056.42 (Fig. 5a) and 27273786 (Fig. 5b). These values can be assumed as scaling coefficients calculating the median value of predicted parameters (source volume, apparent volume, stress drop or $\Delta \sigma \bullet \pi r^{2}$ ) corresponded to the used mass of explosive materials. Each relation showed in Figs. 3a, b, 4a, b were supplemented with maximum and minimum models (dashed-dotted lines) which 
(a)

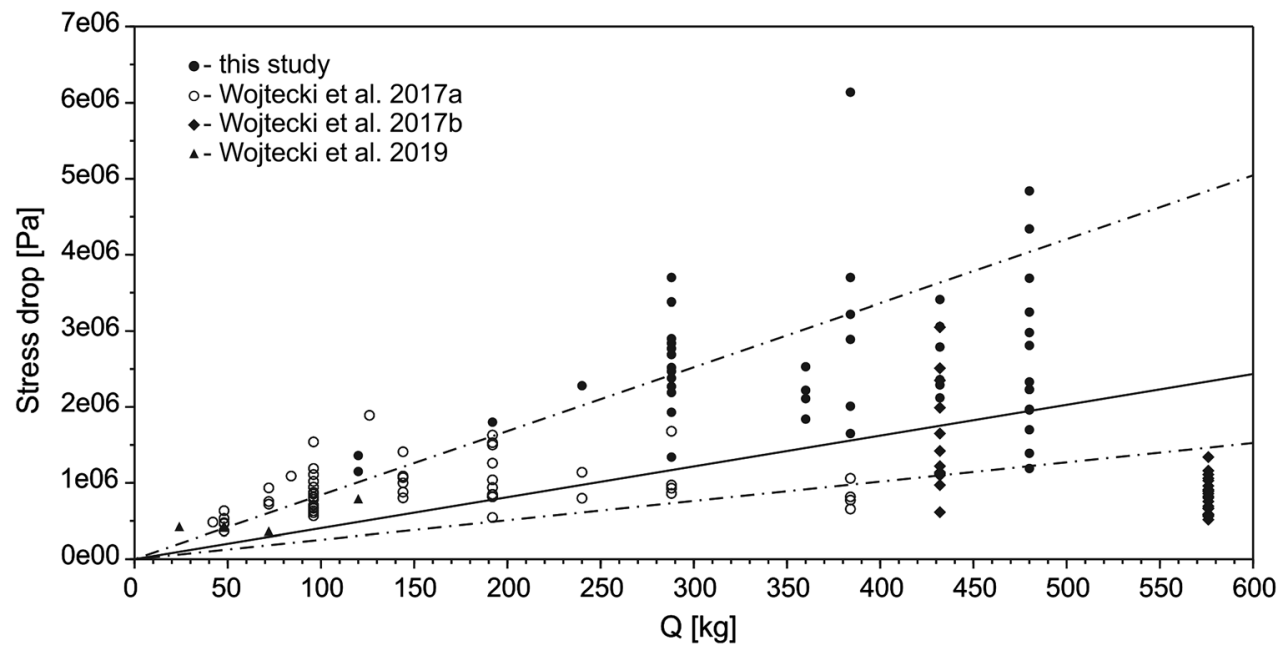

(b)

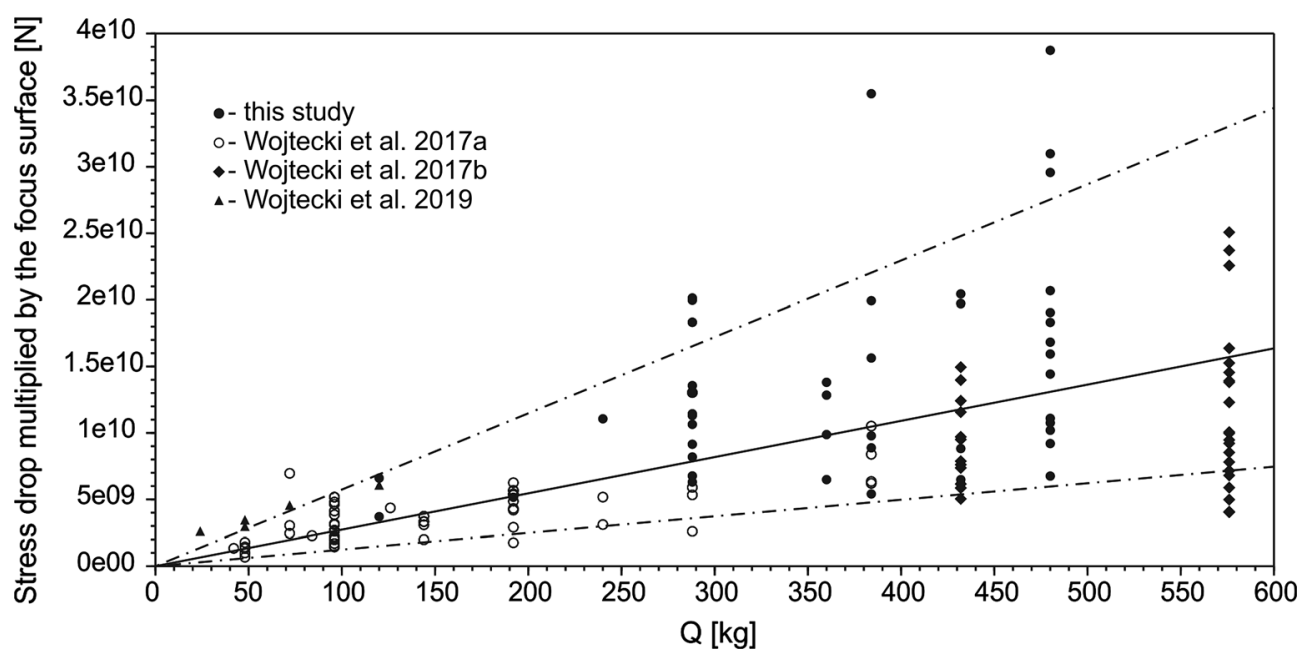

Figure 5

The relation between stress drop and $Q$ (a) and between $\Delta \sigma \bullet \pi r^{2}$ and $Q(\mathbf{b})$

can be used to estimate the maximum or minimum values of expected source parameters (Table 4).

In addition to using spectral parameters to estimate the effectiveness of long-hole destress blasts, we decided to use also the peak particle velocity (PPV) for this purpose. PPV refers to the movement of molecular particles within the ground. This parameter is standardly used to estimate the impact of dynamic loading on underground excavations, correlated with mine tremors. According to the PPV, the influence of vibrations on the stability and support of the excavations can be estimated. On the basis of seismic events recorded in hard coal mines in the Upper Silesian Coal Basin, Mutke et al. (2016) proposed a formula linking the PPV in $[\mathrm{m} / \mathrm{s}]$ with the hypocentral distance $R$ in [m] and the scalar seismic moment $M_{o}$ in $[\mathrm{Nm}]$ :

$$
\log (\mathrm{PPV} \cdot R)=0.66 \log \left(M_{o}\right)-7.4
$$

We decided to normalize this parameter, and for each directly provoked mine tremor, we calculated the PPV at the distance $100 \mathrm{~m}$ from the source $\left(\mathrm{PPV}_{100}\right)$. The previously calculated scalar seismic moment $M_{o}$ was taken into account in calculations 
Table 4

Slopes of the studied models with the maximum and minimum limits

\begin{tabular}{lllll}
\hline & \multicolumn{2}{l}{ Slope values for regression models } & & \\
\cline { 2 - 5 } & Source volume & Apparent volume & Stress drop & $4 \sigma \bullet \pi r^{2}$ \\
\hline Slope (median) & 488.14 & 22987.05 & 4056.42 & 27273786 \\
Slope (maximum) & 956.59 & 50240.82 & 8408.83 & 57373921 \\
Slope (minimum) & 155.32 & 7989.70 & 2542.36 & 12432104 \\
\hline
\end{tabular}

Table 5

The values of $P P V_{100}$ associated with directly provoked mine tremors by the long-hole destress blasting

\begin{tabular}{llrrlr}
\hline No. & $\begin{array}{l}\text { Mass of } \\
\text { explosives }[\mathrm{kg}]\end{array}$ & $\begin{array}{r}\mathrm{PPV}_{100} \\
{[\mathrm{~mm} / \mathrm{s}]}\end{array}$ & No. & $\begin{array}{l}\text { Mass of } \\
\text { explosives }[\mathrm{kg}]\end{array}$ & $\begin{array}{c}\mathrm{PPV}_{100} \\
{[\mathrm{~mm} / \mathrm{s}]}\end{array}$ \\
\hline 1 & 288 & 8.1 & 25 & 384 & 12.6 \\
2 & 288 & 9.3 & 26 & 192 & 7.3 \\
3 & 288 & 7.1 & 27 & 480 & 25.9 \\
4 & 288 & 9.8 & 28 & 360 & 11.5 \\
5 & 288 & 8.3 & 29 & 480 & 11.9 \\
6 & 288 & 12.0 & 30 & 360 & 9.0 \\
7 & 288 & 9.9 & 31 & 480 & 26.9 \\
8 & 288 & 15.4 & 32 & 360 & 10.8 \\
9 & 288 & 11.2 & 33 & 480 & 10.8 \\
10 & 288 & 14.3 & 34 & 360 & 12.6 \\
11 & 288 & 13.4 & 35 & 480 & 13.9 \\
12 & 432 & 15.1 & 36 & 120 & 5.2 \\
13 & 432 & 8.3 & 37 & 480 & 16.8 \\
14 & 432 & 11.4 & 38 & 240 & 12.4 \\
15 & 288 & 15.8 & 39 & 480 & 14.5 \\
16 & 288 & 8.7 & 40 & 120 & 7.3 \\
17 & 432 & 8.0 & 41 & 480 & 11.4 \\
18 & 432 & 13.0 & 42 & 480 & 28.1 \\
19 & 432 & 8.9 & 43 & 480 & 19.9 \\
20 & 384 & 12.9 & 44 & 480 & 15.6 \\
21 & 384 & 14.4 & 45 & 480 & 20.5 \\
22 & 384 & 9.0 & 46 & 480 & 21.0 \\
23 & 384 & 9.8 & 47 & 480 & 17.1 \\
24 & 384 & 8.5 & & & \\
\hline & & & & &
\end{tabular}

(see Table 1). The results of the calculations are collected in Table 5. The $\mathrm{PPV}_{100}$ varies from 5.2 to $28.1 \mathrm{~mm} / \mathrm{s}$ (mean $12.9 \mathrm{~mm} / \mathrm{s}$ ).

Similar to previous parameters, the relationship between $\mathrm{PPV}_{100}$ and mass of fired explosives $(Q)$ has been determined (Fig. 6). The linear model was also determined using linear regression assuming free element as zero. The slope value for this model equals 0.0302 (Fig. 6). As before, this value can be assumed as a scaling coefficient enabling calculation of the median value of predicted $\mathrm{PPV}_{100}$ corresponding to the mass of fired explosives. In the same way, as in case of spectral parameters, the relation $\mathrm{PPV}_{100}=\mathrm{f}(Q)$ was supplemented with the maximum and minimum models (dashed-dotted lines), i.e. with slopes 0.048 and 0.018 , respectively. They can be applied to estimate the maximum and minimum values of expected $\mathrm{PPV}_{100}$.

\section{Discussion and Conclusions}

The longwall mining of coal seam no. 506 in one of the underground hard coal mines in the Polish part of the USCB was planned under complicated geological and mining conditions. This mining was correlated with high seismic activity and a high level of rockburst hazard, so the application of active rockburst prevention was required. The main form of active rockburst prevention was long-hole destress blasting in the roof rocks of coal seam no. 506, executed from the longwall face. The primary purpose of this blasting was to destress the rock mass ahead of the longwall face.

The long-hole destress blasts provoked tremors directly and, in some cases, also in the waiting time. The seismic source parameters of these tremors have been calculated.

The parameters of the tremors provoked directly have been averaged, according to the mass of the explosives used. Low values of the seismic source parameters, except for corner frequency $f_{o}$, are observed where the mass of explosives was the lowest (120 and $192 \mathrm{~kg}$ ). Average values of the seismic source parameters of tremors provoked by the firing of 288, 360, 384 and $432 \mathrm{~kg}$ are close to each other. In these groups, a change in seismic source parameters with the increasing mass of explosives 


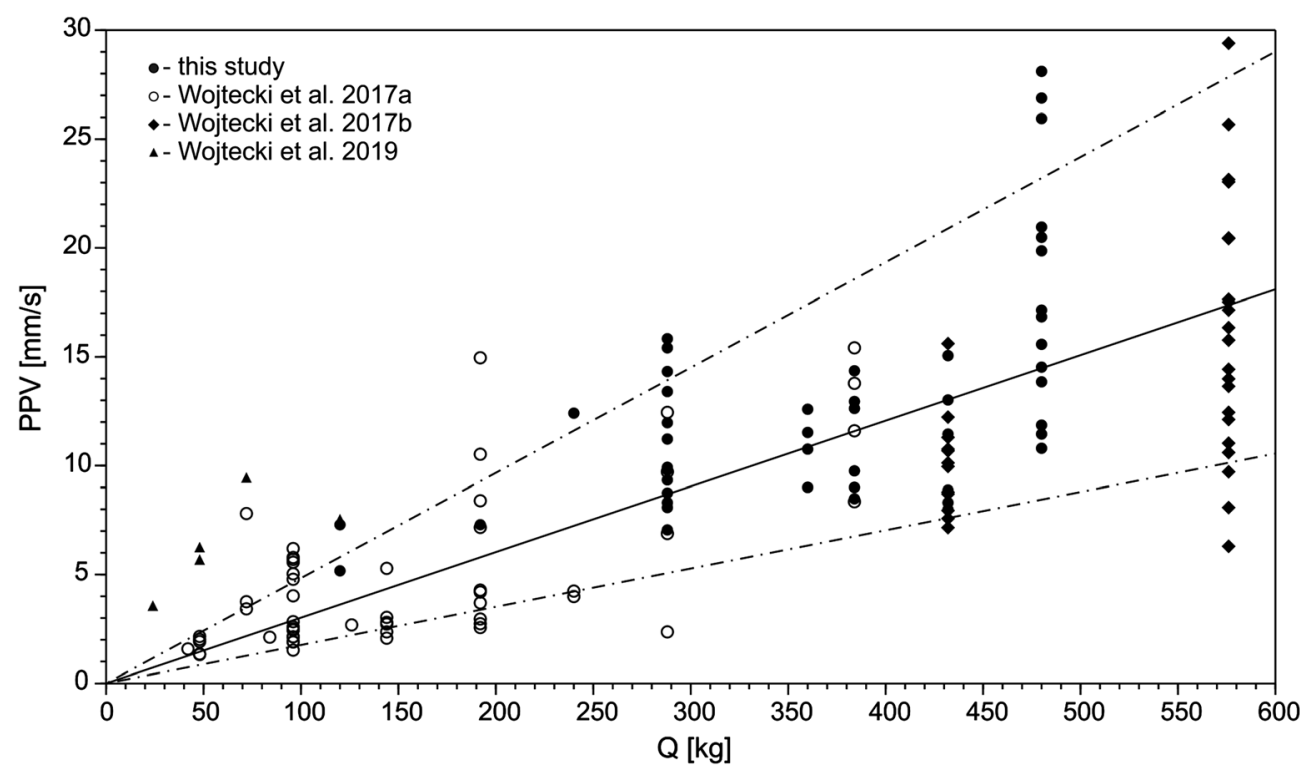

Figure 6

The relation between $\mathrm{PPV}_{100}$ and $Q$

was not so pronounced. However, these blasts were performed under different geological and mining conditions, and so under different stress levels in the rock mass. A blast with the use of a lower mass of explosives, but under high stress level may initiate additional processes in the rock mass, which may be reflected in values of the seismic source parameters. On the contrary, a blast with the use of the higher mass of explosives, but in destressed rock mass, usually has a smaller effect. Average values of the low-frequency spectral level $\Omega_{o}$, the scalar seismic moment $M_{o}$, the moment magnitude $M_{w}$, the seismic energy calculated for P-waves $E_{p}$, the source radius $r$, the source volume $V_{s}$, and the apparent volume $V_{a}$ for tremors occurred directly after firing of $480 \mathrm{~kg}$ of explosives are higher, but the corner frequency $f_{o}$ is lower, and the stress drop $\Delta \sigma$ and the apparent stress $\sigma_{a}$ are generally at a comparable level. Blasts with the highest mass of explosives were performed when the longwall face was experiencing the effects of both the remnant of coal seam no. 418 and the edge of the coal seam no. 502, which created a high stress level in the rock mass. These blasts gave, on average, a better effect. However, blasting with the use of the lower mass of explosives gave in, isolated cases, a comparable effect.
The seismic source parameters of tremors occurred in the waiting time after the blasts were analysed as well. The low-frequency spectral level $\Omega_{o}$, the scalar seismic moment $M_{o}$, the moment magnitude $M_{w}$, the seismic energy calculated for P-waves $E_{p}$, and the source radius $r$ of the strongest tremor $\left(M_{L}=1.60\right)$, which occurred in the waiting time, after blast no. 20, are the highest. Comparing them with the average values for tremors provoked immediately after the detonation of $480 \mathrm{~kg}$ of explosives, $\Omega_{o}$ is higher by about $150.2 \%, M_{o}$-by about $96.2 \%, M_{w}$-by about $11.6 \%, E_{p}$-by about $136.7 \%$, and $r$-by about $53.3 \%$. The corner frequency $f_{o}$ is lower by about $30.6 \%$, and the stress drop $\Delta \sigma$ and the apparent stress $\sigma_{a}$ are at a comparable level. The source volume $V_{s}$ and the apparent volume $V_{a}$ of the strongest tremor in the waiting time are higher by about 48 and $93 \%$, respectively from the average values calculated for tremors provoked immediately after the detonation of $480 \mathrm{~kg}$ of explosives. Only one tremor provoked directly by firing a $480 \mathrm{~kg}$ of explosives (tremor no. 27) has comparable values of the source volume $V_{s}$ and the apparent volume $V_{a}$. The parameters of the two other tremors $\left(M_{L}=1.41\right)$ in the waiting time are similar to those for tremors provoked directly by the detonation 
of $288-432 \mathrm{~kg}$ of explosives, but the low-frequency spectral level $\Omega_{o}$, the corner frequency $f_{o}$, the stress drop $\Delta \sigma$ and the apparent stress $\sigma_{a}$ are slightly lower. However, the second of them has a higher source radius $r(57.1 \mathrm{~m})$. The source volume $V_{s}$ and the apparent volume $V_{a}$ of these two tremors in the waiting time are higher in the comparison with values obtained for tremors provoked directly by the detonation of 288-432 kg of explosives. Generally concerning tremors in the waiting time, the volume of inelastic deformation and the coseismic inelastic strain was in these cases larger.

The relationships between the mass of explosives $Q$ and the source volume $V_{s}$, the apparent volume $V_{a}$, the stress drop $\Delta \sigma$ and the range of area destressed, defined as the stress drop multiplied by the focus surface, were determined. Even a little bit lower stress drop, but on a larger area could be recognized as positive from the rockburst prevention point of view. This comparison shows that increasing the mass of explosives fired causes an increase of inelastic deformation amount, coseismic inelastic strain rate, and the range of area destressed. However, even firing a low mass of explosives is able to provoke a tremor with higher values of investigated parameters.

In addition, developed equations enable to some degree the prediction of the mentioned above parameters depending on the explosives used in a quantitative way. If we accept that destressed blasting releases the accumulated strain energy in the rock mass, then we can use the observed relationship between the total explosive mass of the blasting and the source volume $V_{s}$ and/or the apparent volume $V_{a}$ as the limit of its effectiveness. An analogous situation concerns the observed relationship between the total explosive mass of the blasting and defined in this article range of area destressed. Then all blasts with larger values of mentioned parameters can be accepted as "effective", and stress accumulated in the rock mass was released. In this way, the seismic monitoring of destress blasts can be utilized to check their main goal in the rockburst prevention, i.e. the successful release of the accumulated strain energy.

Furthermore, additional studies on the behaviour of spectral parameters must take place in order to develop a more coherent theory which links the source parameters with the blasts parameters. The presented models can be also applied in future seismic hazard assessment in mines including the prediction of the discussed parameters. What is surprisingly positive, based on this study and those carried out previously (Wojtecki et al. 2017a, b, 2019), is that it appears that estimating seismic source parameters after destress blasts may deliver important information on the rock fracturing process during blasting and its effectiveness. An analogous situation concerns the peak particle velocity, associated with the immediately provoked tremors (without delay) presented in the article. If a greater PPV was obtained than it would result from the mass of fired explosives, the energy release due to the relaxation of stress in the rock mass took place, and so the destress blasting was more effective. But further analysis is necessary.

Open Access This article is licensed under a Creative Commons Attribution 4.0 International License, which permits use, sharing, adaptation, distribution and reproduction in any medium or format, as long as you give appropriate credit to the original author(s) and the source, provide a link to the Creative Commons licence, and indicate if changes were made. The images or other third party material in this article are included in the article's Creative Commons licence, unless indicated otherwise in a credit line to the material. If material is not included in the article's Creative Commons licence and your intended use is not permitted by statutory regulation or exceeds the permitted use, you will need to obtain permission directly from the copyright holder. To view a copy of this licence, visit http://creativecommons.org/licenses/by/4.0/.

Publisher's Note Springer Nature remains neutral with regard to jurisdictional claims in published maps and institutional affiliations.

\section{REFERENCES}

Aki, K., \& Richards, P. G. (1980). Quantitative seismology. Theory and methods. San Francisco: Freeman.

Andrews, D. J. (1986). Objective determination of source parameters and similarity of earthquakes of different size: Earthquake source mechanics. In S. Das, J. Boatwright \& C.H. Scholz (Eds.) (Vol. 6, pp. 259-267). Washington, D.C.: Am. Geophys. Union.

Baruah, S., Bora, P. K., Duarah, R., Kalita, A., Biswas, R., Gogoi, N., \& Kayal, J. R. (2012). Moment magnitude (MW) and local 
magnitude (ML) relationship for earthquakes in Northeast India. Pure and Applied Geophysics, 169(11), 1977-1988.

Brune, J. N. (1970). Tectonic stress and the spectra of seismic shear waves from earthquakes. Journal Geophysical Research, 75, 4997-5009.

Cichowicz, A. (1981). Determination of source parameters from seismograms of mining tremors and the inverse problem for a seismic source. Publications of the Institute of Geophysics of PAS (Vol. 11). Warszawa (in Polish).

Dubiński, J., Mutke, G., \& Stec, K. (1996). Focal mechanism and source parameters of the rockburst in Upper Silesian Coal Basin. Acta Montana IRSM AS CR, 9(100), 17-26.

Dubiński, J., \& Wierzchowska, Z. (1973). Methods for the calculation of tremors seismic energy in the Upper Silesia. Research Works of Central Mining Institute (Vol. 591). Katowice (in Polish).

Gibowicz, S. J., \& Kijko, A. (1994). An introduction to mining seismology. San Diego: Academic Press.

Hanks, T. C., \& Kanamori, H. (1979). A moment magnitude scale. Journal of Geophysical Research, 84, 2348-2350.

Knotek, S., Matusek, Z., Skrabis, A., Janas, P., Zamarski, B., \& Stas, B. (1985). Research of geomechanics evaluation of rock mass due to geophysical method. Ostrava : VVUU. (in Czech).

Konicek, P., Konecny, P., \& Ptacek, J. (2011). Destress rock blasting as a rockburst control technique. Proceedings of the 12th International Congress on Rock Mechanics, Bejing (pp. 1221-1226).

Konicek, P., Soucek, K., Stas, L., \& Singh, R. (2013). Long-hole destress blasting for rockburst control during deep underground coal mining. International Journal of Rock Mechanics and Mining Sciences, 61, 141-153.

Kwiatek, G., Martínez-Garzón, P., \& Bohnhoff, M. (2016). HybridMT: A MATLAB/shell environment package for seismic moment tensor inversion and refinement. Seismological Research Letters, 87(4), 964-976.

Lizurek, G., Rudziński, Ł, \& Plesiewicz, B. (2015). Mining induced seismic event on an inactive fault. Acta Geophysica, 63(1), 176-200.

Madariaga, R. (1976). Dynamics of an expanding circular fault. Bulletin of Seismological Society of America, 66, 639-666.

McGarr, A., Bicknell, J., Sembera, E., \& Green, R. W. E. (1989). Analysis of exceptionally large tremors in two gold mining districts of South Africa. Pure and Applied Geophysics, 129(3/4), 295-307.

Mendecki, A. J. (1993). Real time quantitative seismology in mines. Keynote lecture: Proceedings of the 3rd International Symposium on Rockburst and Seismicity in Mines (R.P. Young, ed.), Kingston, Canada, Balkema, Rotterdam (pp. 287-296).

Mendecki, A. J. (1997). Seismic monitoring in mines. London: Chapman and Hall.
Mutke, G., Masny, W., \& Prusek, S. (2016). Peak particle velocity as an indicator of the dynamic load exerted on the support of underground workings. Acta Geodynamica et Geomaterialia, 13(4), 367-378.

Orlecka-Sikora, B., Lasocki, S., Lizurek, G., \& Rudziński, Ł. (2012). Response of seismic activity in mines to the stress changes because of mining induced strong seismic events. International Journal of Rock Mechanics \& Mining Sciences, 53, 151-158.

Rudziński, Ł, Cesca, S., \& Lizurek, G. (2016). Complex rupture process of the 19 March 2013, "Rudna" mine (Poland) induced seismic event and collapse in the light of local and regional moment tensor inversion. Seismological Research Letters, 87(2A), 274-284.

Snoke, J. A. (1987). Stable determination of (Brune) stress drops. Bulletin of Seismological Society of America, 64, 1295-1317.

Srinivasan, C., Sivakumar, C., \& Gupta, R. N. (2005). Source parameters of seismic events in a coal mine in India. Proceedings of 27th Seismic Research Review: Ground-Based Nuclear Explosion Monitoring Technologies (pp. 653-662).

Stein, S., \& Wysession, M. (2003). An introduction to seismology, earthquakes, and earth structure. New York: Wiley.

Trifu, C. I., Urbancic, T. I., \& Young, R. P. (1995). Source parameters of mining-induced seismic events: An evaluation of homogeneous and inhomogeneous faulting models for assessing damage potential. Pure and Applied Geophysics, 145(1), 3-27.

Website: https://www.nitroerg.pl/en/products/emulinit-pm.html

Wojtecki, Ł., \& Gołda, I. (2019). Analysis of stress level during longwall mining of a coal seam with the use of seismic effect method. IOP Conference Series: Earth and Environmental Science (Vol. 261, no. 012057).

Wojtecki, Ł, \& Konicek, P. (2016). Estimation of active rockburst prevention effectiveness during longwall mining under disadvantageous geological and mining conditions. Journal of Sustainable Mining, 15(1), 1-7.

Wojtecki, Ł, Konicek, P., Mendecki, M. J., Gołda, I., \& Zuberek, W. M. (2019). Geophysical evaluation of effectiveness of blasting for roof caving during longwall mining of coal seam. Pure and Applied Geophysics. https://doi.org/10.1007/s00024019-02321-1

Wojtecki, Ł, Konicek, P., Mendecki, M. J., \& Zuberek, W. M. (2017a). Application of seismic parameters for estimation of destress blasting effectiveness. Proceedings of ISRM European Rock Mechanics Symposium EUROCK, 191, 750-760.

Wojtecki, Ł, Mendecki, M. J., \& Zuberek, W. M. (2017b). Determination of destress blasting effectiveness using seismic source parameters. Rock Mechanics and Rock Engineering, 50(12), 3233-3244. 